УДК [338.012; 339.138]

\title{
Ян Цзяньфэй
}

\section{НЕЙРОТЕХНОЛОГИИ: ОЦЕНКА ПЕРСПЕКТИВ РАЗВИТИЯ В КИТАЕ}

Проанализировано текущее состояние и тенденции развития нейротехнологий в маркетинге Китая. В частности, были затронуты такие вопросы, как роль эмоций в процессе принятия решений о покупке жителями Китая, степень рациональности этих решений, информированность общественности Китая о нейротехнологиях, ее отношение к использованию нейротехнологий в маркетинговой деятельности китайскими фирмами в коммерческих целях и т.д. Результаты исследования показали, что роль эмоций в процессе принятия решений о покупке китайскими потребителями недооценена. Механизм функционирования разработанных маркетинговых раздражителей не хорошо воспринят китайскими потребителями, что и ограничивает эффектность применяемых нейротехнологий при улучшении маркетинговых раздражителей. Информированность о нейротехнологиях и нейромаркетинге среди жителей Китая находится пока на низком уровне, но их отношение к использованию этих технологий в коммерческих целях носит довольно положительный характер. Статистический анализ показывает, что положительное отношение может быть связано со степенью осведомленности о нейротехнологиях. Автором были разработаны рекомендации по преодолению проблем, препятствующих развитию нейротехнологий, в маркетинге Китая.

Ключевые слова: нейротехнологии и нейромаркетинг, эмоции, рациональность, информированность, отношение китайской общественности, проблемы и перспективы.

DOI: 10.35634/2412-9593-2019-29-5-621-629

\section{Введение}

Одна из важнейших целей для современных предприятий - максимизация прибыли. Применение нейротехнологий в маркетинге напрямую стимулирует рост объема продаж продуктов и косвенным образом влияет на увеличение прибыли предприятий. Именно поэтому развитие знаний и внедрение данной области маркетинга важны для многих предприятий не только в Китае, но и во всем мире.

Многие фирмы уже применяют нейромаркетинг в своей коммерческой деятельности. Так, нейротехнологии используют PepsiCo, The Coca-Cola Company, Frito-Lay (Lay's), Fox, Hyundai, Disney, P\&G, Pfizer, Unilever, Google, Facebook, Mercedes Benz, Software, Yahoo, Audi и другие. После появления нейромаркетинга на китайском рынке китайские фирмы тоже обратили внимание на данную науку. На фоне стратегических распоряжений китайского правительства о расширении ассортимента продукции, повышении качества продуктов на национальном рынке и оптимизации продуктовой структуры для лучшего удовлетворения запросов китайских потребителей использование нейротехнологий для достижения вышеуказанных целей становится очень актуальным.

Актуальность данной статьи обусловлена нарастающим спросом со стороны китайских компаний на нейромаркетинг и нейротехнологии, отсутствием на сегодняшний день достоверной информации об отношении китайских покупателей к использованию нейромаркетинга и нейротехнологий. В рамках исследования был выделен ряд гипотез, которые были проверены с помощью статистического анализа. Проверка гипотез на практике осуществлена на основе опроса методом анкетирования респондентов.

\section{1. Цель и методология исследования}

Цель исследования: сформировать заключение о развитии нейротехнологий в КНР на основе анализа потребительских настроений и общественного мнения. В рамках исследования необходимо решить следующие задачи:

- выявить факторы, влияющие на покупательское поведение жителей КНР;

- определить уровень информированности китайских потребителей о нейротехнологиях и дать оценку качеству их знаний;

- исследовать отношение граждан Китая как потребителей к применению нейротехнологий в коммерческих целях. 
Для получения результатов были использованы общенаучные и эмпирические методы анализа. В качестве эмпирического метода было проведено анкетирование с использованием интернет-анкеты (доступ возможен через мобильный телефон и со стационарного компьютера) в 2018 г. Респондентам были заданы вопросы с одним вариантом ответа, с несколькими вариантами ответа и вопросы на базе шкалы Ликерта. Дистанционное анкетирование было проведено среди населения 20 разных провинций КНР (включая города центрального подчинения), выборка охватывает жителей всех уровней образования (от школы до третьего уровня высшего образования). Сбор анкет осуществлялся с помощью онлайн-системы анкетирования «Wenjuan», обработка данных проводилась в программе IBM SPSS Statistics 24 с использованием следующих статистических методов: частотный анализ, сравнение средних и др.

Всего проведено анкетирование 157 респондентов - физических лиц. Среди опрошенных было 86 респондентов женского пола $(54,8 \%)$ и 71 респондент мужского пола $(45,2 \%)$. Большинство респондентов - молодые люди в возрастном диапазоне 17-35 лет (среди которых в возрастной диапазон 17-25 лет попадает 44,6\%, а в диапазон 26-35 лет попадает 33,8 \%). Только небольшая часть респондентов попадает в диапазоны: меньше 17 лет, 36-45 лет и старше 45 лет (суммарно не превышают $22 \%$ ). По уровню образования: 45,3 \% респондентов имеют первый уровень (бакалавриат), 19,8 \% - второй уровень (магистратура) и 18,5\% имеют третий уровень высшего образования (аспирантура). По критерию обеспеченности денежными средствами более половины респондентов $(66,3 \%)$ имеют достаточный бюджет на жизнь и могут позволить себе приобрести бытовую технику и даже автомобиль.

На основе вышеизложенного можно сделать выводы о специфике выборки - опрошенные в основном молодые люди в возрасте 17-35 лет, среди опрошенных респондентов женского пола немного больше, чем респондентов мужского пола. Другой особенностью выборки является то, что респонденты, имеющие высшее образование, доминируют в выборке. Можно сделать вывод, что опрошенная группа проявляет интерес к новым технологиям и изменениям, имеет доступ к новым знаниям, потребность в новых впечатлениях и различных товарах, обладает необходимыми навыками для поиска и сбора информации через Интернет.

\section{2. Гипотезы исследования и результаты их проверки}

При проведении исследования автором был выдвинут ряд гипотез, которые были проверены с использованием методов математической статистики.

Гипотеза 1. Роль эмоций в процессе принятия решений о покупке китайскими потребителями недооиенена.

На рис. 1 и 2 представлены данные об основных мотивах покупателей при выборе товаров в общем и при выборе товаров разных категорий. На рис. 3 представлены данные об оценке покупателями собственной степени рациональности при совершении покупок.

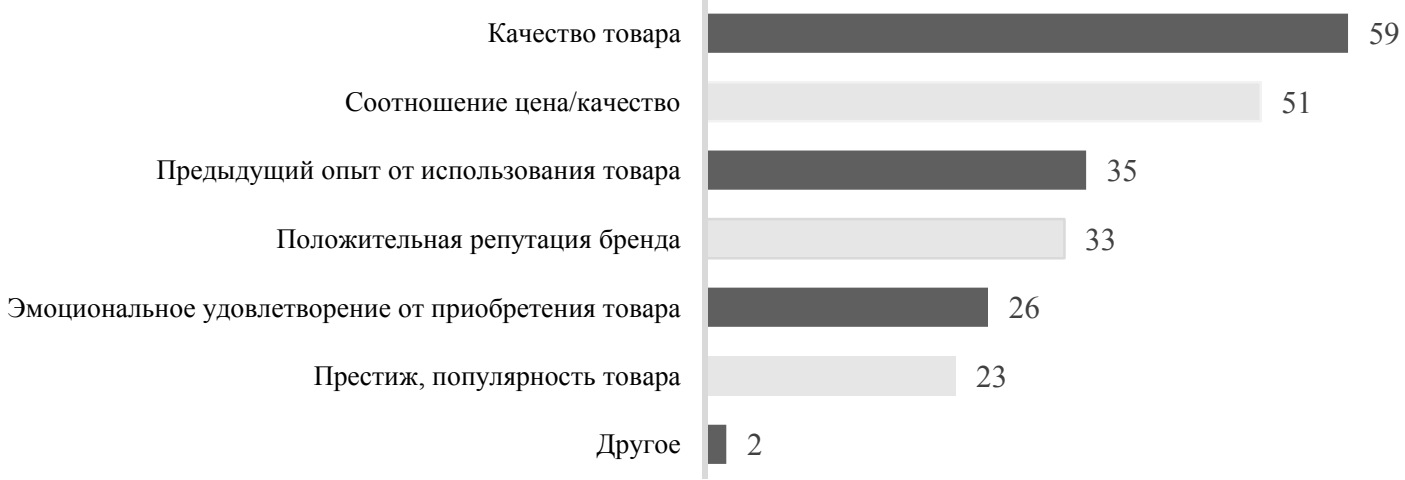

Количество респондентов, человек

Рис. 1. Мотивы, влияющие на решение о покупке (возможен выбор нескольких вариантов ответа) 


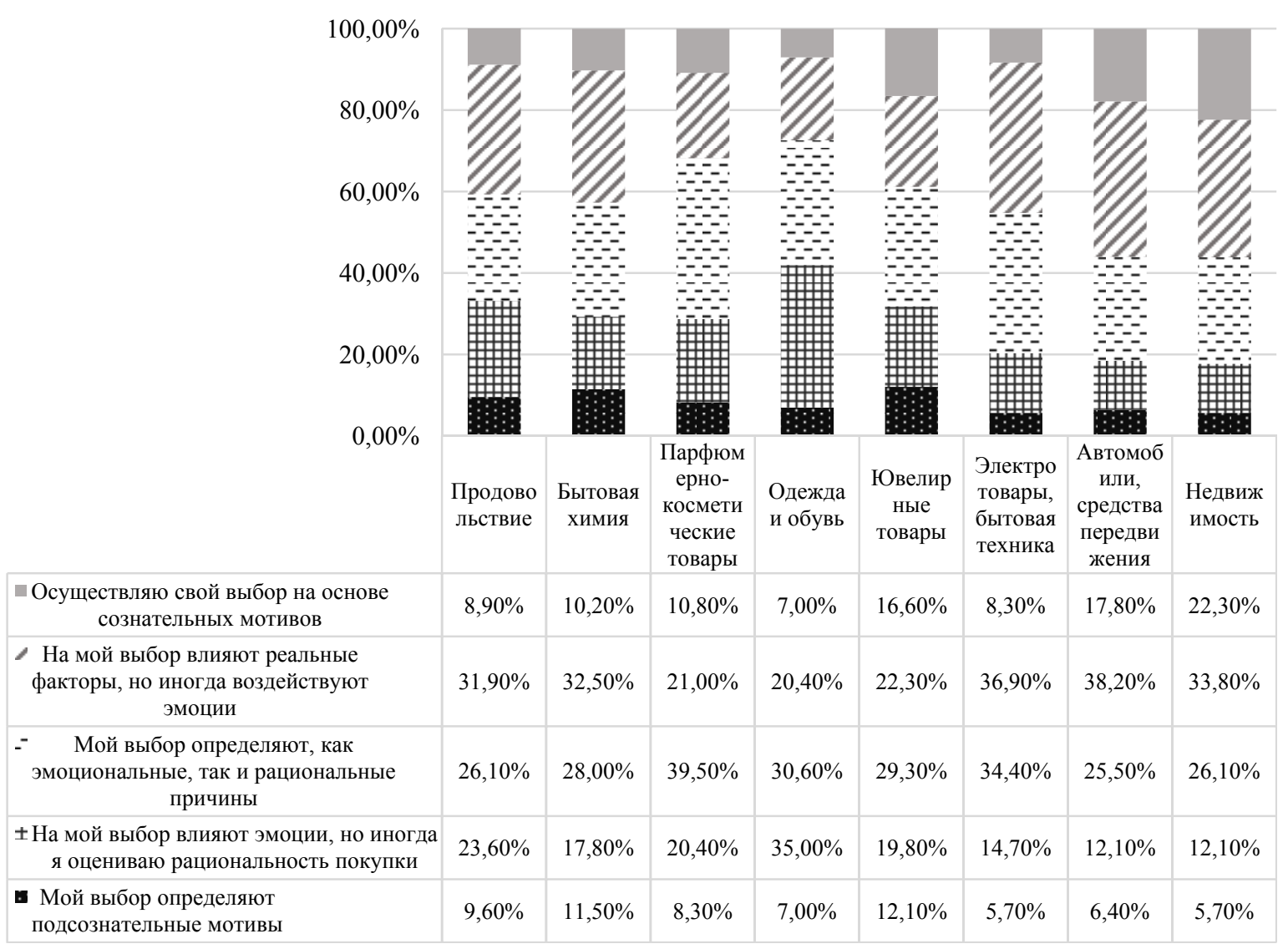

Рис. 2. Основные мотивы для принятия решения о покупке и оценка покупателями собственной степени рациональности при покупке разных групп товаров

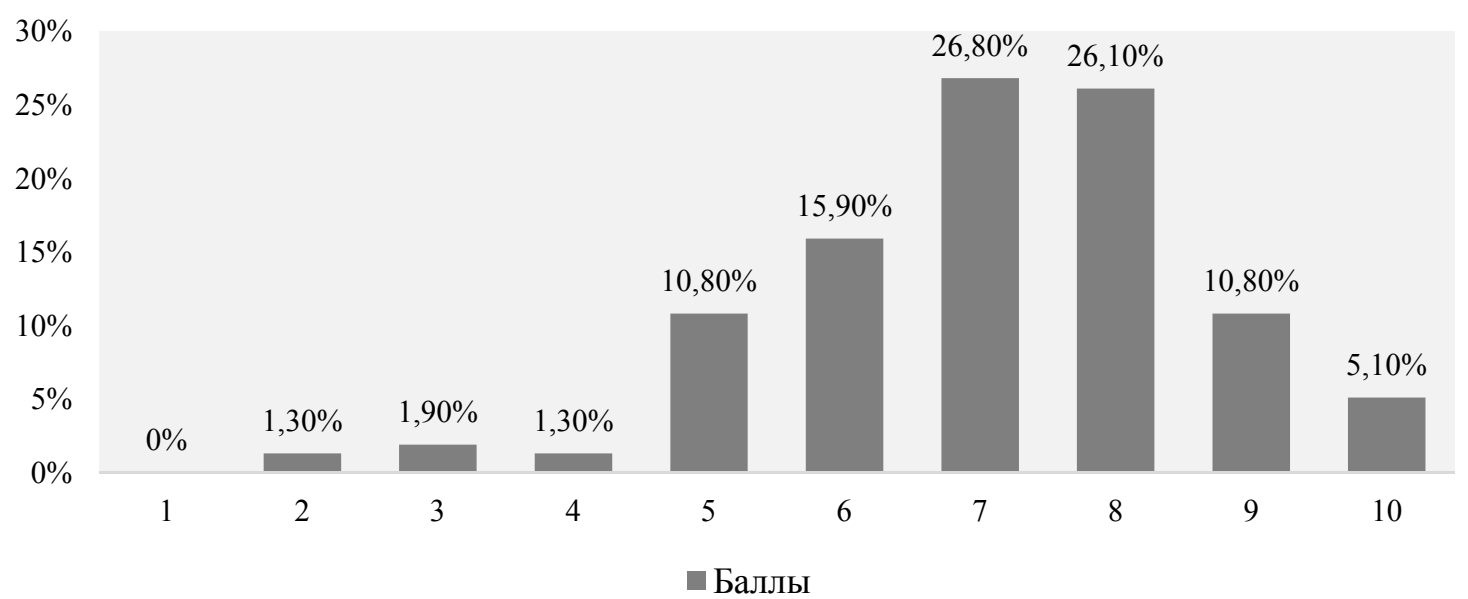

Рис. 3. Общая оценка покупателями собственной степени рациональности при совершении покупок

Исходя из ответов, представленных на рис. 1, для большинства покупателей самыми важными факторами, которыми они руководствуются при принятии решений о покупке, являются «качество товара» (выбор 59 респондентов) и «соотношение цена/качество» (выбор 51 респондента). С одной стороны, данный результат связан с уровнем материального благополучия опрошенной группы. Потому что лица, имеющие ограниченный бюджет, которого им едва хватает на жизнь, вряд ли будут обращать большое внимание на качество товаров. Они более прагматичны по сравнению с обладателями высокого достатка. С другой стороны, это является доказательством того, что большинство людей считает, что 
они принимают решение о покупке на основе логического мышления, принимая во внимание соотношение качества и цены товаров (после сравнения соответствующих показателей разных товаров одного функционального назначения). Только 26 респондентов (16 \%) считают, что эмоциональное удовлетворение стимулирует их принимать решение о покупке. Другими словами, не все респонденты осознают роль своих эмоций в принятии решений о покупке. По данным нейромаркетинговых исследований, для принятия решения о покупке требуется всего лишь 2,5 секунды (в среднем). За такой короткий период времени человек не способен принять решение на основе логического мышления (на основании сравнительного анализа параметров товаров, например, цены, качества и функционала) на сознательном уровне. Таким образом, китайские потребители недооценивают важность эмоций в принятии решений о покупке и их роль в стимулировании к выбору того или иного товара.

На рис. 2 показаны результаты опроса об основных мотивах для принятия решений о покупке разных категорий товаров. Мы можем ранжировать все товары по уровню цен на них (в восходящем порядке): продовольствие, бытовая химия, парфюмерно-косметические товары, одежда и обувь, ювелирные товары, электротовары и бытовая техника, автомобили, средства передвижения и недвижимость. Варианты ответов от верхнего к нижнему приведены с постепенным снижением степени влияния сознательных мотивов (реальных факторов) и повышением степени подсознательных (или даже бессознательных) мотивов (эмоциональных факторов) на принятие решения о покупке. Во-первых, из полученных данных можно сделать вывод о том, что для любой категории товаров число респондентов, считающих, что подсознательные мотивы (эмоции) определяют их выбор (кроме продовольствия и бытовой химии), незначительно. Во-вторых, при покупках продовольствия, бытовой химии, электротоваров и бытовой техники, автомобилей и недвижимости часть респондентов (около 30 \%) выбирает реальные факторы, а эмоции служат лишь вспомогательным толчком. Тем не менее причины, почему реальные факторы для этих покупателей доминируют при покупках этих категорий товаров, могут и различаться. Продовольствие и бытовая химия считаются предметами повседневного обихода, поэтому их качество и эффективность занимают первое место при принятии решений о покупке. Эмоции тоже в определенной степени влияют, но уступают реальным факторам по уровню важности. Цены на электротовары и бытовую технику, автомобили и недвижимость весьма высоки. Именно поэтому люди не могут их купить только под воздействием эмоций. Заметим, что при покупках парфюмерно-космических товаров, одежды и обуви, ювелирных товаров, эмоции оказывают большее влияние на принятие решений о покупке, чем при приобретении других категорий товаров. Это видно из полученных данных (рациональность снижается примерно на 10 \%). Товары этих категорий предпочитают женщины. Что совпадает с утверждением, что на женщин более эффективно воздействуют эмоциональные драйверы, так как у этой категории покупателей доминирует эмоциональное мышление (Karlinsky N., Patrick M., 2011). В целом 70-80\% респондентов считают, что на принятие ими решения о покупке влияют как эмоциональные, так и реальные факторы. Соотношения этих двух факторов могут различаться в зависимости от конкретной категории товаров, но, в общем, чаще всего доминируют реальные факторы.

Данный вывод совпадает с баллами, представленными на рис. 3, где общая оценка покупателями собственной степени рациональности при совершении покупок у 80 \% опрошенных попадает в интервал 5-8 баллов. Это означает, что, на взгляд большинства наших респондентов, степень их рациональности варьируется от 50 \% до 80 \%. Другими словами, доминируют рациональные факторы при некотором влиянии эмоций. Картина на рис. 3 не соответствует нормальному распределению (скорее, правостороннее распределение). Большинство респондентов дает высокую оценку своей рациональности. Отсюда можно сделать вывод о чрезмерной уверенности китайских покупателей в рациональности своих мотивов при покупке товаров и о недооценке роли эмоций в принятии решений о покупке. Данный вывод косвенным образом доказывает, что китайские потребители не в полной мере осознают, каким образом маркетинговые стимулы могут влиять на принимаемые ими решения о покупке, в том числе недооцененными оказываются нейротехнологии, применяемые в маркетинге для улучшения маркетинговых стимулов.

Гипотеза 1 принимается.

Гипотеза 2. Маркетинговые раздражители для китайской общественности имеют более важное значение в сравнении с самой продукцией при стимулировании принятия решений о покупке.

В анкете был разработан ряд вопросов для выявления степени влияния разных факторов на принятие решений о покупке. Эти факторы были разделены на две группы. В первую группу вошли 
маркетинговые раздражители, а во вторую - характеристики самой продукции. Нейротехнологии применяются в разных элементах маркетингового комплекса (например, в дизайне упаковки продуктов, в разработке рекламы, в дизайне логотипа и в оценке эффективности разработанных маркетинговых элементов). Соответственно, нам важно оценить, какую роль играют разработанные маркетологами раздражители в процессе принятия решений о покупке покупателями. Если важность самих этих раздражителей в принятии решений о покупке велика, то эффектность применяемых нейротехнологий в совершенствовании маркетинговых элементов будет более очевидна.

В результате обработки собранных данных установлено, что среди всех маркетинговых раздражителей программы лояльности, скидки и подарки потребителям оказывают наибольшее влияние на принятие решений китайским потребителем (табл. 1). Интернет-реклама занимает второе по важности место при принятии решений о покупке для китайской общественности (благодаря бурному развитию в Китае интернет-торговли). Телевизионная и радиореклама имеют несколько меньшее значение. Таким образом, реклама в разных формах в Китае распространена, и она действительно влияет на покупательские решения потребителей. Но все равно, по мнению жителей Китая, маркетинговые раздражители уступают по значимости самой продукции в степени воздействия на принятие решений о покупке. С учетом уровня совокупных доходов населения Китая приоритет при принятии решений о покупке должен быть у показателя «цена/качество». Данный вывод совпадает с результатами опроса. Большинство наших респондентов считает, что качество товара и сервиса оказывают наибольшее влияние на принятие ими решений (самая высшая оценка 4,16 баллов).

Таблица 1

\section{Степень важности разных маркетинговых раздражителей и характеристик продукции} для китайской общественности в принятии решений о покупке

\begin{tabular}{|l|c|}
\hline \multicolumn{1}{|c|}{ Маркетинговые раздражители } & $\begin{array}{c}\text { Степень важности в принятии } \\
\text { решений о покупке }\end{array}$ \\
\hline \multicolumn{1}{|c|}{} & \\
\hline 1. Телевизионная и радио-реклама & 3,45 \\
\hline 2. Наружная реклама и реклама на транспорте & 2,96 \\
\hline 3. Реклама в точках продаж & 3,25 \\
\hline 4. Интернет-реклама & 3,52 \\
\hline 5. Программы лояльности, скидки, подарки потребителям & 3,73 \\
\hline 6. Изображения на упаковке, материал упаковки & 3,43 \\
\hline 7. Логотип бренда, слоган & 3,16 \\
\hline \multicolumn{2}{|l|}{ Природа (характеристики) самой продукции } \\
\hline 8. Качество товара и сервиса & \\
\hline
\end{tabular}

На основании вышеизложенного мы можем прийти к выводу, что, по мнению опрошенных респондентов, маркетинговые раздражители не играют решающей роли в принятии решений о покупке, хотя и оказывают определенное влияние. С одной стороны, это доказывает, что на данном этапе маркетинговые раздражители действительно работают, но их необходимо совершенствовать для усиления их эффективности в стимулировании продаж продуктов. С другой стороны, это также показывает, что, хотя маркетологи имеют возможность применять нейротехнологии для повышения эффективности существующих маркетинговых раздражителей, на данном этапе для большинства китайских потребителей из-за экономических ограничений само качество товара и сервиса является основным фактором при принятии решений о покупке. Другими словами, из-за объективных рыночных условий и ограничений, связанных с уровнем материального благополучия китайского населения, применение нейротехнологий в маркетинге Китая может не дать ожидаемого положительного результата (не позволит существенно увеличить объемы продаж продуктов).

Гипотеза 2 не принимается.

Гипотеза 3. Граждане Китая плохо информированы о нейротехнологиях и нейромаркетинге.

Данные на рис. 4 отражают степень информированности населения Китая о нейротехнологиях и нейромаркетинге. 


\begin{tabular}{|l|l|l|l|l|l|l|}
\hline \multicolumn{1}{|c|}{$80,00 \%$} & & & \\
\hline
\end{tabular}

Рис. 4. Информированность о нейротехнологиях и нейромаркетинге граждан КНР

По статистическим данным, $42,7 \%$ опрошенных не знали, встречали ли они ранее термины «нейромаркетинг» и «нейротехнологии». Они не имеют понятия, существует ли такая наука. А $48,5 \%$ респондентов признали, что определенно раньше не встречали эти термины или скорее всего не встречали. Эти данные могут служить доказательством того, что преобладающая доля китайского населения ранее вовсе не обращала внимания на данную науку (до заполнения данной анкеты). По третьему вопросу 52,3 \% респондентов признали, что они не просматривают статьи, связанные с нейротехнологиями. С одной стороны, данный результат может отражать низкую степень популярности регулярного чтения в китайском обществе. С другой стороны, косвенным образом объясняет, почему большая часть опрошенных либо совсем не знает о существовании нейромаркетинга и соответствующих технологий, либо не уверена, сталкивались ли они раньше с нейромаркетингом и его основными инструментами (нейротехнологиями). Ответы опрошенных на последние два вопроса усиливают предположение: степень информированности среди китайской общественности пока низка. Большинство из опрошенных - молодые люди, имеющие высшее образование. Тем не менее из результатов анкетирования следует, что 46,4 \% опрошенных вообще не получили информацию об инструментарии нейромаркетинга в процессе своего обучения. Ответ на последний вопрос в какой-то степени детерминирован, потому что низкая информированность ограничивает возможность использования данной науки на практике. Таким образом, можно сделать вывод о том, что граждане Китая плохо информированы о нейротехнологиях и нейромаркетинге. Гипотеза 3 принимается.

Гипотеза 4. Китайская общественность нейтрально относится к использованию предприятиями нейротехнологий в своих коммерческих целях (в маркетинговой деятельности).

Для изучения отношения жителей Китая к использованию нейротехнологий в коммерческих целях были сформулированы следующие утверждения:

1) считаю, что использование нейротехнологий позволяет получить более объективные данные о потребностях покупателя;

2) считаю использование нейротехнологий естественной коммерческой практикой для повышения конкурентоспособности фирмы. 


\begin{tabular}{|c|c|c|}
\hline \multicolumn{3}{|l|}{$100,00 \%$} \\
\hline \multicolumn{3}{|l|}{$80,00 \%$} \\
\hline $60,00 \%$ & & \\
\hline $40,00 \%$ & & \\
\hline $20,00 \%$ & 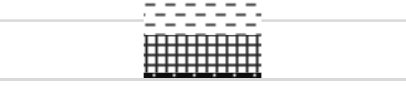 & (n) \\
\hline $0,00 \%$ & $\begin{array}{c}\text { Считаю, что использование } \\
\text { нейротехнологий позволяет } \\
\text { получить более объективные } \\
\text { данные о потребностях } \\
\text { покупателя }\end{array}$ & $\begin{array}{c}\text { Считаю использование } \\
\text { нейротехнологий естественной } \\
\text { коммерческой практикой для } \\
\text { повышения } \\
\text { конкурентоспособности фирмы }\end{array}$ \\
\hline Совершенно согласен & $4,50 \%$ & $14,70 \%$ \\
\hline Скорее согласен & $40,80 \%$ & $45,20 \%$ \\
\hline - Не знаю, согласен или не согласен & $39,50 \%$ & $31,90 \%$ \\
\hline д Скорее не согласен & $12,70 \%$ & $5,10 \%$ \\
\hline Совершенно не согласен & $2,60 \%$ & $3,20 \%$ \\
\hline
\end{tabular}

Рис. 5. Отношение китайской общественности к использованию предприятиями нейротехнологий в коммерческих целях (в маркетинговой деятельности)

Ответы на первый вопрос отражают перспективы использования нейротехнологий в коммерческой сфере, потому что 45,3\% респондентов рассматривают их в качестве новых подходов в практике предприятий для получения объективной информации о потребностях покупателя. Но здесь существует часть опрошенных (39,5\%), которые не могут дать конкретную оценку практике использования предприятиями нейротехнологий, возможно, из-за отсутствия соответствующих знаний о нейротехнологиях или информации о применении предприятиями нейротехнологий в маркетинговой деятельности. В сравнении с первым вопросом на $15 \%$ больше респондентов уверено, что применение нейротехнологий способствует повышению конкурентоспособности предприятий. Здесь только около $32 \%$ опрошенных выразили свое нейтральное мнение. Если соединить ответы на эти два вопроса, мы можем прийти к выводу, что, в общем, китайская общественность позитивно относится к использованию предприятиями нейротехнологий в коммерческих целях, а не нейтрально или отрицательно. Гипотеза 4 не принимается.

Гипотеза 5. Отношение китайской общественности к применению нейротехнологий зависит от степени ее информированности (осведомленности).

Для того чтобы проверить выдвинутую гипотезу о зависимости отношения китайской общественности к использованию нейромаркетинга от ее информированности о данной науке, был проведен статистический анализ для выявления тренда между этими переменными. Положительный результат данного анализа будет означать, что корреляция между вышеизложенными переменными существует. Следовательно, отношение населения Китая к использованию нейротехнологий зависит от степени информированности. Отрицательный результат будет означать, что подобной корреляции между переменными не существует и информированность (осведомленность) китайской общественности о нейротехнологиях не влияет на ее отношение к их использованию. Рассчитаем коэффициент корреляции Спирмена для выявления этой зависимости (см. табл. 2).

Можем отметить наличие корреляции между двумя парами переменных (первая пара: «отношение к личному участию в экспериментах» и «степень информированности»; вторая пара: «отношение к юридическому запрету» и «степень информированности»). Исходя из полученных данных вывод автора следующий: для тех респондентов, которые имеют более глубокие знания о нейромаркетинге и его технологиях, информированность о нейромаркетинге и нейротехнологиях связана с их отношением к личному участию в нейромаркетинговых экспериментах и к юридическому запрету на нейротехнологии. Иными словами, более полные знания влияют на желание принять личное участие в экспериментах с применением нейротехнологий и на собственную оценку степени законности нейротехнологий в Китае. Данная корреляция особенно заметна среди тех респондентов, которые непосредственно в своей работе используют (или использовали) нейромаркетинг и его инструментарий. Благодаря глубокому пониманию данной науки они в состоянии оценить риск участия в экспериментах и перспективу развития нейротехнологий в Китае. 
Таблица 2

Коэффициент корреляции Спирмена. Переменная 1- степень информированности о нейротехнологиях среди китайской общественности, переменная 2 - отношение к их использованию

\begin{tabular}{|c|c|c|c|c|c|}
\hline Утверждение & $\begin{array}{l}\text { Ранее } \\
\text { не встречал } \\
\text { терминов } \\
\text { «нейро- } \\
\text { маркетинг», } \\
\text { «нейро- } \\
\text { технологии» }\end{array}$ & $\begin{array}{l}\text { Знаю } \\
\text { о существовании } \\
\text { нейротехнологий } \\
\text { и нейромаркетинга, } \\
\text { но целенаправленно } \\
\text { информацию } \\
\text { не ищу }\end{array}$ & $\begin{array}{c}\text { Регулярно } \\
\text { просматри- } \\
\text { ваю статьи } \\
\text { в журналах } \\
\text { о нейротех- } \\
\text { нологиях }\end{array}$ & $\begin{array}{l}\text { Узнал } \\
\text { об ин- } \\
\text { струмента- } \\
\text { рии нейро- } \\
\text { маркетинга } \\
\text { в процессе } \\
\text { обучения } \\
\end{array}$ & $\begin{array}{c}\text { Использую } \\
\text { нейро- } \\
\text { маркетинг } \\
\text { в своей } \\
\text { работе }\end{array}$ \\
\hline $\begin{array}{l}\text { Считаю } \\
\text { использование } \\
\text { нейротехнологий } \\
\text { естественной } \\
\text { коммерческой } \\
\text { практикой }\end{array}$ & 0,042 & 0,127 & $-0,071$ & 0,104 & $-0,057$ \\
\hline $\begin{array}{l}\text { Лично готов } \\
\text { участвовать } \\
\text { в экспериментах } \\
\text { по использованию } \\
\text { нейротехнологий за } \\
\text { удовлетворительную } \\
\text { плату }\end{array}$ & $-0,002$ & 0,029 & $0,233^{*}$ & $0,181^{*}$ & $0,219 * *$ \\
\hline $\begin{array}{l}\text { Считаю } \\
\text { использование } \\
\text { нейротехнологий } \\
\text { недопустимым } \\
\text { в коммерческих } \\
\text { целях (подлежащим } \\
\text { юридическому } \\
\text { запрету) }\end{array}$ & $-0,068$ & 0,01 & $0,165^{*}$ & $0,169^{*}$ & $0,227 * *$ \\
\hline
\end{tabular}

** Означает, что на уровне 0,01 (двойной хвост) корреляция значительна.

* Означает, что на уровне 0,05 (двойной хвост) корреляция значительна.

На основании вышеизложенного анализа мы можем сделать вывод, что часть китайской общественности выражает свое отношение к использованию нейротехнологий, опираясь на свои знания или пройденные курсы во время обучения. Гипотеза 5 принимается.

\section{Заключение}

Подводя итоги исследования, можно констатировать, что в целом жители Китая завышают роль своей рациональности при оценке принятия покупательских решений. Информированность китайской общественности относительно нейротехнологий пока находится на невысоком уровне. Нераспространенность нейротехнологий прямым образом отражает текущее состояние нейромаркетинга в Китае. Отношение к использованию нейротехнологий частично зависит от степени осведомленности населения о данной технологии. С другой стороны, невысокая информированность о нейротехнологиях не привела к отрицательному отношению к нейромаркетингу. Вероятность юридического запрета использования нейротехнологий в коммерческих целях в Китае низка, потому что на данном этапе жители Китая выражают положительное отношение к их использованию.

Факторы, препятствующие развитию нейротехнологий в Китае, могут быть следующими: ограниченная эффективность функционирования маркетинговых раздражителей при текущем уровне материального благополучия большинства китайского населения и низкой осведомленности о нейротехнологиях. У развития нейромаркетинга есть перспективы, так как китайская общественность положительно относится к использованию нейротехнологий в коммерческих целях и существует возможность поддерживать позитивное отношение населения страны к коммерческому использованию 
нейротехнологий с помощью распространения этих технологий в Китае. С учетом текущего уровня развития нейротехнологий в маркетинге Китая можно рекомендовать вузам КНР активнее внедрять программы по нейроэкономике в учебные программы, предприятиям распространять информацию о применении нейротехнологий в своей маркетинговой деятельности, чтобы информировать население о существовании этих технологий в маркетинге Китая и устранить общественный страх перед нейротехнологиями и нейромаркетингом.

\section{СПИСОК ЛИТЕРАТУРЫ}

1. Молчанов Н.Н., Муравьева О.С., Галай Н.И. Нейротехнологии: оценка перспектив развития в России // Вестн. Удм. ун-та. Сер.: Экономика и право. 2019. Т. 29, вып. 2. С. 142-151.

2. Ma Qingguo, Wang Xiaoyi. From Neuroeconomics and Neuromarketing to Neuromanagement // Journal of Management Engineering, 2006(3). P. 129-132.

3. Ma Qingguo, Fu Huijian, Bian Jun. Neuroindustrial Engineering: A New Stage of Industrial Engineering Development // Management World, 2012(6). P. 163-179.

4. Molchanov N.N., Korableva O.N., Muraveva O.S., Galay N.I. Neuromarketing as an Innovative Approach to Market Research of Consumer Behavior // Proceedings of the 29th International Business Information Management Association Conference "Education Excellence and Innovation Management through Vision 2020: From Regional Development Sustainability to Global Economic Growth". Viena, 2017. P. 2489-2500.

5. Yan Li. The Research of the Current Situation of Neuromarketing // Foreign Economies and Management. 2011. 33(5). P. 25-32.

6. Zhou Xiulan. The Dilemma of the Research and Application of Neuromarketing. The Market Forum, 2016(1). P. 63-64.

7. Zhu Guowei. Neuromarketing Cognition, Buying Decision and brain. Hunan: Hunan University Press. 2012. P. $227-233$.

Поступила в редакцию 11.09.2019

Ян Цзяньфэй, аспирант

ФГБОУ ВО «Санкт-Петербургский государственный университет»

199034, Россия, г. Санкт-Петербург, Университетская набережная, д. 7-9

E-mail:believeyou.yjf@yandex.com

\section{Jianfei Yang \\ NEUROTECHNOLOGIES: EVALUATION OF DEVELOPMENT PROSPECTS IN CHINA}

DOI: $10.35634 / 2412-9593-2019-29-5-621-629$

The article analyzes the current state and development trends of neurotechnologies in China's marketing. In particular, the following issues are raised: the role of emotions in the decision-making process on the purchase by the Chinese people, the degree of rationality of these decisions, the public awareness of China about neurotechnologies, its attitude to the use of neurotechnologies in marketing by Chinese firms for commercial purposes, etc. The results of the study showed that the role of emotions in the decision-making process on the purchase by Chinese consumers is underestimated. The functioning mechanism of the developed marketing stimuli is not well received by Chinese consumers, which limits the effectiveness of the applied neurotechnologies while improving marketing stimuli. Awareness of neurotechnologies and neuromarketing among Chinese residents is still low, but their attitude to the use of these technologies for commercial purposes is quite positive. Statistical analysis shows that a positive attitude may be related to the degree of awareness of neurotechnologies. The author developed recommendations to overcome the problems that impede the development of neurotechnologies in China's marketing.

Keywords: neurotechnologies and neuromarketing, emotions, rationality, awareness, attitude of the Chinese public, problems and prospects.

Received 11.09.2019

Jianfei Yang, postgraduate student

St. Petersburg State University

Universitetskaya naberezhnaya, 7-9, St. Petersburg, Russia, 199034

E-mail: believeyou.yjf@yandex.com 